\title{
A Bibliometric Overview of the International Journal of Interactive Multimedia and Artificial Intelligence
}

\author{
Hugo Baier-Fuentes ${ }^{1}$, Jesús Cascón-Katchadourian², M.A Martínez³, Enrique Herrera-Viedma4, José M. \\ Merigó ${ }^{5,6} *$
}

${ }^{1}$ Department of Business Administration, Universidad Católica de la Santísima Concepción. Av. Alonso de Ribera 2850, Concepción (Chile)

${ }^{2}$ Department of Information and Communication. Faculty of Communication and Documentation. Colegio Máximo de Cartuja, 18071, Granada (Spain)

${ }^{3}$ Department of Social Work and Social Services, University of Granada, Granada (Spain)

${ }^{4}$ Department of Computer Science and Artificial Intelligence, University of Granada, Av. Periodista Daniel Saucedo s/n, Granada, (Spain)

${ }^{5}$ School of Systems, Management and Leadership, Faculty of Engineering and Information Technology, University of Technology Sydney, 81 Broadway, Ultimo, 2007 NSW (Australia)

${ }^{6}$ Department of Management Control and Information Systems, School of Economics and Business, University of Chile, Av. Diagonal Paraguay 257, 8330015 Santiago (Chile)

Received 20 November 2018 | Accepted 28 November 2018 | Published 1 December 2018

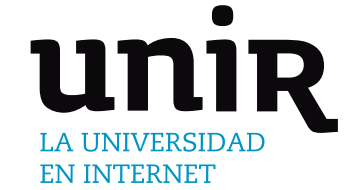

The International Journal of Interactive Multimedia and Artificial Intelligence (IJIMAI) published its first Bibliometrics, Web Of issue ten years ago. Currently, IJIMAI is indexed in the important database Emerging Sources Citation Index. This paper aims to identify, through a mapping of science, those most relevant aspects of the structure of Science, VOS Viewer. publications made during the first 10 years of IJIMAI. Using VOSviewer software, the structural maps of the IJIMAI publications are analysed according to techniques such as bibliographic coupling, co-citations and cooccurrence of keywords. In addition, the evolution of the publications, citations and an analysis of the most cited papers of the journal are presented. The results show that IJIMAI has experienced a remarkable growth of both publications and citations in the last five years. We also observe that IJIMAI does not only capture the attention of the Spanish scientific community, but also of emerging countries such as India and Iran and emerging Latin American countries such as Colombia. With a such increasing behaviour, it is expected in the coming years that IJIMAI will position itself among the best journals with similar scientific scope.

\section{INTRODUCTION}

\begin{abstract}
A $\mathrm{s}$ stated in its access platform, the International Journal of AInteractive Multimedia and Artificial Intelligence (IJIMAI hereinafter), pretends to be an open access point to relevant research on advances in Artificial Intelligence tools or tools that use Artificial Intelligence with interactive multimedia techniques. IJIMAI published its first issue in December 2008, under the direction of its editors, Dr. Jesús Soto Carrión and Dr. Elisa García Gordo. This issue published research from diverse areas of knowledge, such as Medical Diagnosis, Semantic Metadata, Nature Conservancy and Intelligence perception. Until 2011, IJIMAI kept publishing an annual number. The period 2012 published 3 issues and finally, since 2013, it has kept publishing

* Corresponding author.

E-mail addresses: hbaier@ucsc.cl (Baier-Fuentes), jesuscascon@ gmail.com (Cascón-Katchadourian), mundodesilencio@ugr.es (Martínez), viedma@decsai.ugr.es (Herrera-Viedma),jmerigo@ fen.uchile.cl (Merigó).
\end{abstract}

4 issues per year. The year 2015 was specially important since the journal was indexed in the Emerging Sources Citation Index (ESCI hereinafter), considered an important database in the Web of Science (WoS hereinafter).

In 2018, IJIMAI celebrates its tenth anniversary, which stimulated our interest in carrying out a bibliometric analysis of all the publications made by the journal. According to Cobo et al. [1], Bibliometrics is a set of methods used to study the impact of a particular field, the impact of a set of researchers or a particular article. Among the main methods used in a Bibliometrics is performance analysis and science mapping [2]. The first one focuses on assessing the impact of scientific actors on a bibliographic database. Keep in mind that scientific actors involve countries, universities, departments, researchers. On the other hand, science mapping intended to show the structural and dynamic aspects of a field of research using techniques such as bibliographic coupling [3], the co-citations of documents [4], citation, co-authorship or coocurrence of keywords. In line with the above, we want to emphasize that the objective of this contribution is to identify, through a science mapping the most relevant structural aspects of the publications made in IJIMAI. For this, this study uses the VOSviewer Software [5]. 
It is important to note that advances in Computer Science and the Internet has intensified the popularity of these techniques among researchers [6], and therefore, at present it is very common to find a combination of performance analysis and / or science mapping applied for example, to specific fields of studies, such as Management [7], Economics [8], International Entrepreneurship [9] or Knowledge Management [10]. In recent years, these analyses have also become common in journals when they celebrate a significant anniversary. These analyses are interesting since they provide some general and historical results that allow the development of a retrospective evaluation [11]. Among some of the journals that have published these analyses we could/can name, for example, Information Sciences in the celebration of its fifty years [12], European Journal of Marketing in recognition of its forty years, International Journal of Intelligent Systems in its thirty years [13], Knowledge-Based Systems at the age of twenty-five years [14], Journal of Product Innovation Management, or more recently, Journal of Knowledge Management, in the celebration of his twenty years [15] [16]. Finally, keep in mind many other journals have already developed a bibliometric description to celebrate a special anniversary [17] [18].

This article is structured as mentioned below. Section II reviews the bibliometric methods, but in a special way, science mapping is introduced. Section III presents the results including several analysis of co-citations, bibliographic coupling, co-authorship and the cooccurrence of keywords. Finally, section IV summarizes the main findings and conclusions of the document.

\section{MethodS}

This study performs a bibliometric analysis of the IJIMAI publications between 2008 and 2018. For this, data from the Web of Science belonging to Clarivate Analytics was collected. Note that the WoS contains a compilation of several citation databases, transforming WoS into the world's leading citation database that covers more than 18,000 high-impact journals. Note however, that there are several other citation databases in the world, such as Scopus, EconLit, Scielo, among others.

Bibliometrics is generally defined as the science that quantitatively studies bibliometric material [19]. Currently, it involves a variety of techniques and methodologies, including performance analysis and science mapping [20], the latter also known as bibliometric mapping. This methodology is an important research topic in the field of Bibliometrics [21], and focuses on finding representations of intellectual connections from a dynamically changing repository of scientific knowledge [22]. Our study seeks to analyse the structural aspects of scientific research published in the 10 years of IJIMAI, although we also disclose information about the most cited papers of the journal.

The advancement of information technologies has allowed this technique to become popular with force. Thanks to this, a wide range of software tools to analyse the bibliographic information has been developed. These include, for example, CiteSpace II [23], Bibexcel [24], VantagePoint [25], VOSViewer software [5], the latter being the one used in this study.

VOSViewer software builds the scientific maps based on some techniques based on bibliographic coupling, co-citations of documents, analysis of co-authorship or analysis of co-words. Note that bibliographic coupling [3] [26] [27] analyses the documents citing the same third document, while the analysis of co-citations [28] [4] focuses on the cited documents. The co-authorship analysis focuses on the authors and their affiliations to study social structure and collaborative networks [29] [30]. Finally, the co-words analysis focuses on the most important words or keywords of the documents, allowing a field of research to be structured conceptually [31] [32] [33].
Note also that the graphical visualization delivered by VOSviewer software is made through network structures, where the size of a circle shows the relevance of an element and the network connections allow identification of the most closely linked elements. The place of the circles and the colours are used to group the elements. Finally, keep in mind that VOSviewer software is an open-source bibliometric mapping tool, which can be easily downloaded from the site http:// www.vosviewer.com/.

\section{RESULTS}

\section{A. Evolution of Publications, Citations and Most Cited Papers of IJIMAI}

The first issue of IJIMAI was published in 2008. During its 10 years of circulation, it has published 325 documents, which have received appointments at least 400 times, according to data of WoS in autumn 2018. In WoS its h-index is 7, there are seven publications that have received 7 citations or more. Fig. 1 presents the evolution of publications since 2008. We should point out that IJIMAI is indexed in WoS from 2015, and its citation evolution cannot be well visualized in WoS.

During its first 4 years, IJIMAI published a number per year. The year 2012 published 3 annual issues. 2013 is the year in which it begins to publish 4 issues per year. In 2015 IJIMAI is indexed in the database Emerging Sources Citation Index (ESCI) provided by Clarivate Analytics, one of the citation databases that is part of the WoS. This allowed IJIMAI to overcome the barrier of the 40 studies in the same year, and of the 50 studies during the following two years. One explanation for this is that the journals indexed in ESCI database, and consequently in WoS database, are distributed and exposed to more and different researchers in various institutions around the world [34].

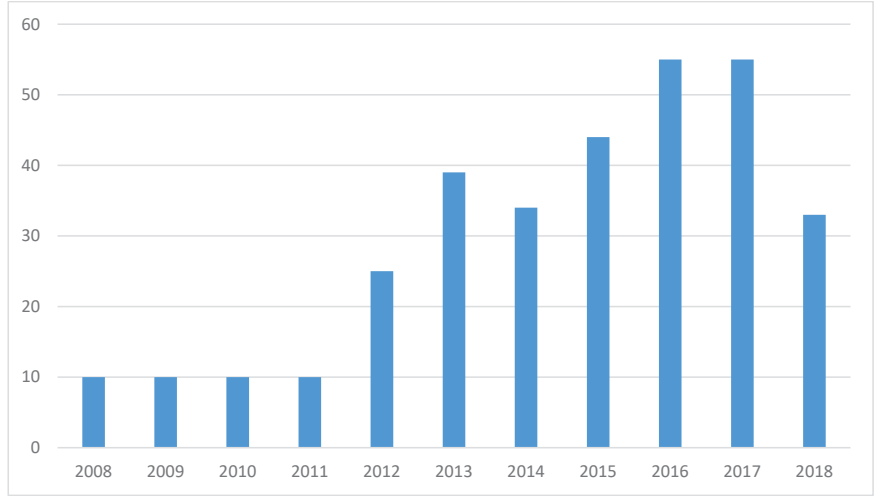

Fig. 1. Annual number of papers published in IJIMAI.

Additionally, we complete the analysis of WoS citations with information provided by Google Scholar. In Fig. 2, we show the citation report of IJIMAI according to Google Scholar. We observe that IJIMAI presents a remarkable h-index of 20 with 2046 citations received from 2013. Therefore, IJIMAI shows a remarkable growth of citations in the last five years as it is shown in the figure.

On the other hand, IJIMAI has published several documents that in total, have been cited more than 400 times by documents from different disciplines. In this sense, it is important to analyse the most cited articles of the journal. Table I presents the twenty-five most cited articles of IJIMAI. The indicators used in the table are defined in the footer. 
TABLE I. THE 25 MOST CITED DOCUMENTS IN IJIMAI

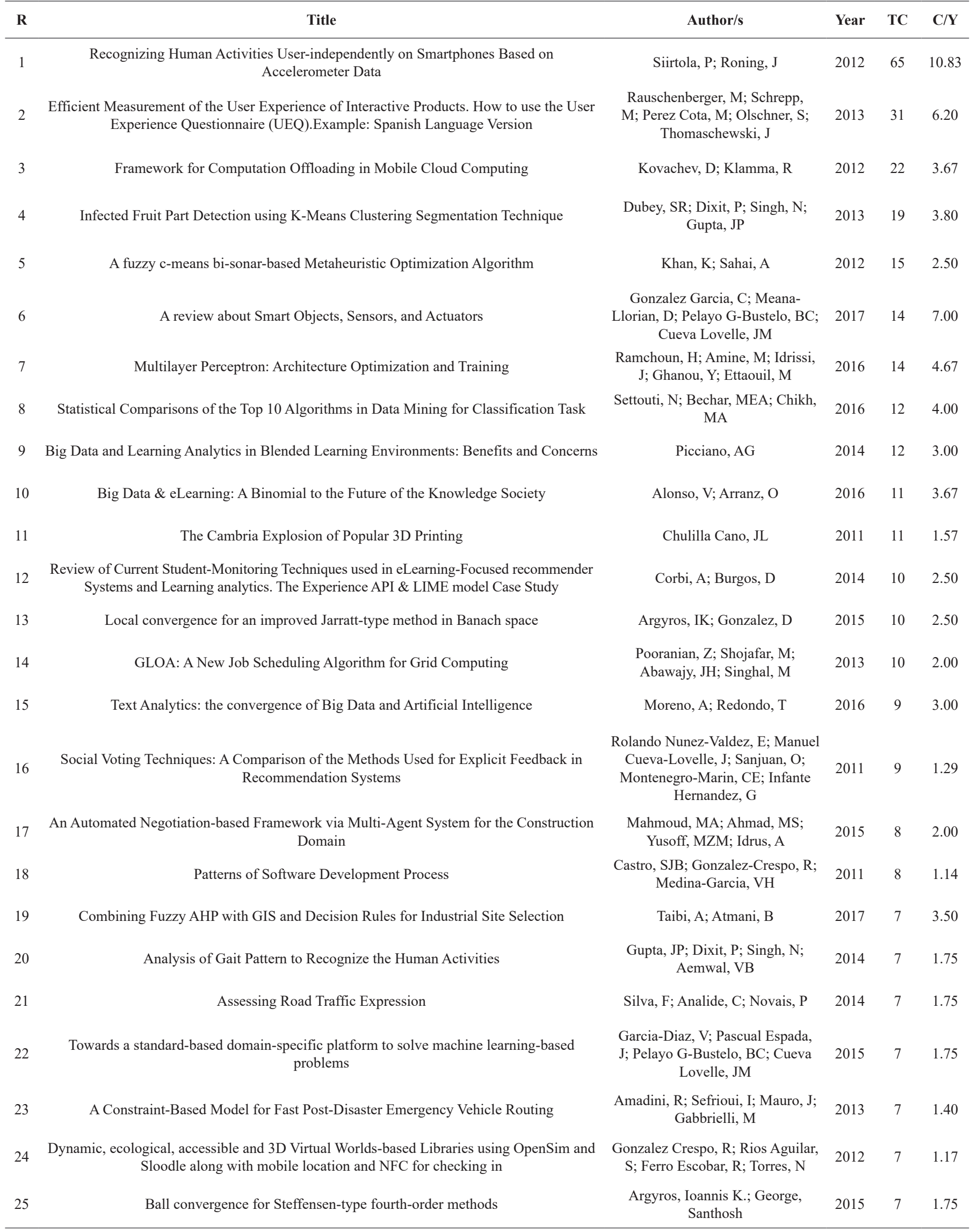

Abbreviations: $\mathrm{R}=$ Rank; $\mathrm{TC}=$ Total citations $\mathrm{C} / \mathrm{Y}$ Cites per year. 


\begin{tabular}{lrr}
\hline & Total & Desde 2013 \\
\hline Citas & 2100 & 2046 \\
Índice h & 20 & 20 \\
Índice i10 & 58 & 56
\end{tabular}

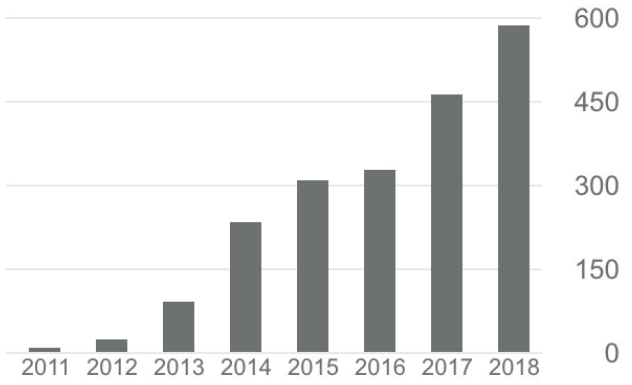

Fig. 2. Citation report of IJIMAI in Google Scholar.

\section{B. Mapping Science of IJIMAI Publications}

As previously mentioned, scientific mapping shows structural aspects of scientific research, becoming, therefore, an important methodology in the field of Bibliometrics [21]. Scientific mapping in practice, is a network structure often used to model the interaction between different scientific actors, such as authors, journals, keywords, references, among others [35]. In this study, therefore, a scientific mapping is presented that tries to analyze the most representative structures and connections between the different actors that have published during the 10 years of IJIMAI. Note that this analysis is presented in terms of techniques such as co-citations, bibliographic coupling and co-occurrence of keywords. For this, the VOSviewer software [5] is used, which has been developed specifically to build and visualize science mappings from files obtained from bibliographic databases, such as WoS, Scopus, PubMed and RIS [35].

Taking into account the above, the co-citations of the journals cited in IJIMAI are analysed. Note in this case, that co-citation occurs when two documents published in different journals receive a citation from the same third document from another journal. Fig. 3 that allows to perform this analysis, presents the information using a threshold of five citations and the hundred most representative co-citations links.

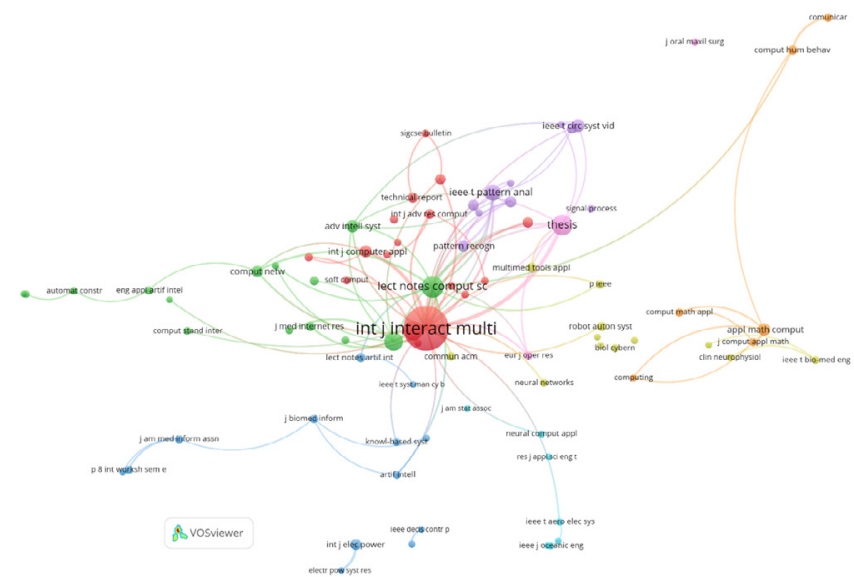

Fig. 3. Co-citation of journals in IJIMAI: minimum citation threshold of 5 and 100 links.

Note that the IJIMAI self-citations are easily observed occupying the centre of the map. This is not surprising, since it is very common in most journals, people developing science in a particular framework use close information sources. However, you can also see that computer journals are very influential. Among them, Lecture Notes in Computer Science, Communications of the ACM, Lecture Notes in Artificial Intelligence, Soft Computing. Also note the presence and influence of journals from other disciplines, but which are clearly linked to computer science. Such is the case of Journal of Biomedical Informatics or Journal of the American Medical Informatics Association.

Another interesting analysis to perform is the co-citation of authors. On the map presented in Fig. 4, it is noted to those authors with the highest number of citations and their connections with other authors. Fig. 4 is constructed with a threshold of five citations and the one hundred most representative links of IJIMAI.

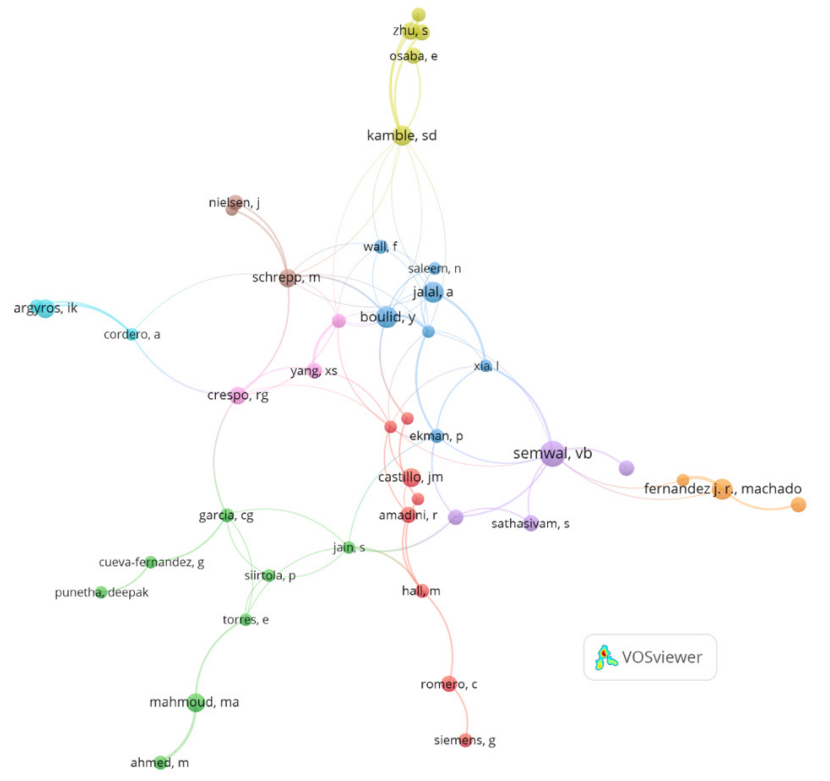

Fig. 4. Co-citation of authors cited in IJIMAI: minimum citation threshold of 5 and 100 links.

Note that there are several authors cited in the journal, but there is no clarity regarding a nucleus of authors that stand out in IJIMAI. Probably this is a consequence of the youth of the journal, and it is expected, therefore, that the most outstanding authors in the disciplines on which IJIMAI focuses will become a space in the same journal. Even so, some of the authors that stand out most in the map of cocitations of authors are, Semwal, V.B., Castillo, J.M., Ekman, P., Boulid, Y., among several others.

Another interesting subject to evaluate in this study is the bibliographic coupling of authors that publish in IJIMAI. Remember that the bibliographic coupling studies the authors of two documents that cite the same third document. Note that the connected documents appear on the map but not the third one, unless you also have a significant degree of bibliographic coupling through other documents [13]. In summary, the map presented in Fig. 5 shows the most productive authors among the entire set of IJIMAI documents.

This figure has the advantage of showing how the most productive authors of IJIMAI connect. Remember that the definition of the bibliographic coupling technique indicates that researchers who are close to each other tend to cite the same publications. Therefore, the interpretation of the figure allows us to highlight several clusters with authors that lead some lines of research in the journal. As it is logical, these authors tend to cite the same publications. For example, authors Thomaschewski, J., Taghezout, N. and Verdu, E. that notoriously form a cluster that develop a line of research. 


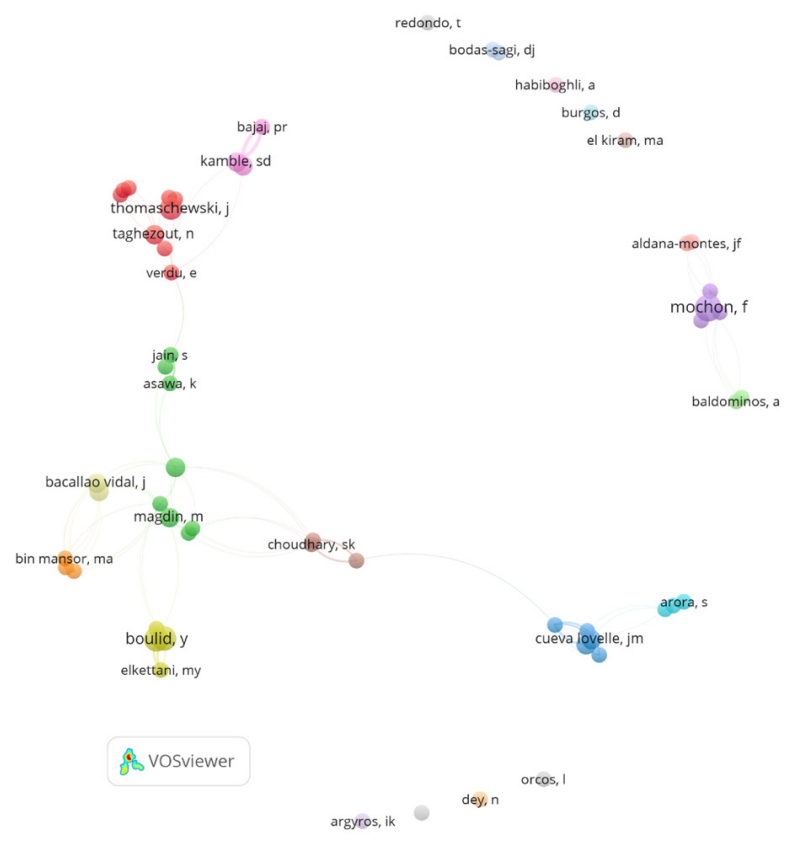

Fig. 5. Bibliographic coupling of authors publishing in IJIMAI: minimum publication threshold of 2 and 100 links.

As well as the previous analysis, it is also interesting to observe how the institutions that publish in the journal are coupled bibliographically. For this, Fig. 6 displays the data considering a minimum threshold of two documents and one hundred connections.

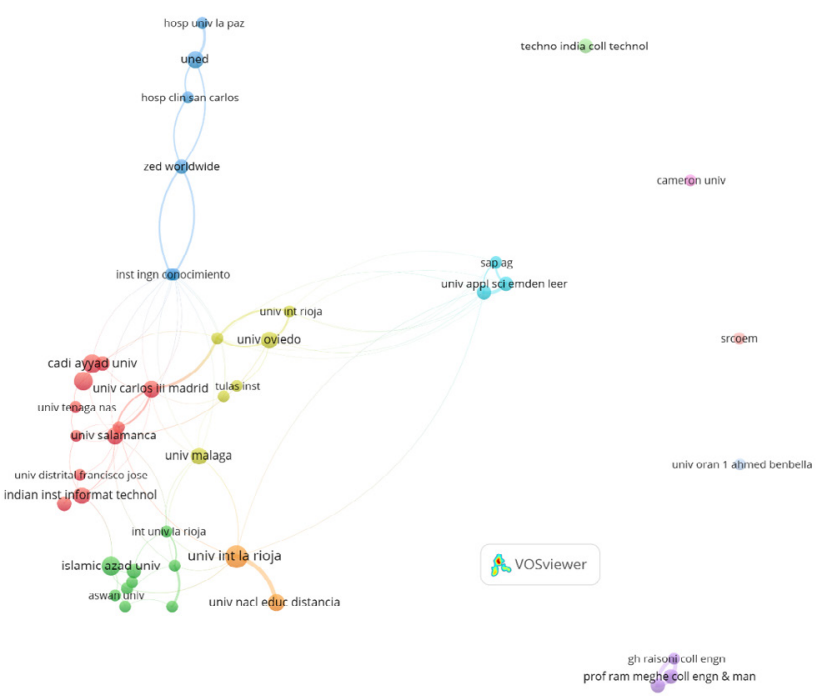

Fig. 6. Bibliographic coupling of institutions publishing in IJIMAI: minimum publication threshold of 2 and 100 links.

Fig. 6 shows the leading institutions in the publications in IJIMAI and their connections. As in the previous analysis, the visualization of this figure represents the trends in research carried out by the institutions that publish in the journal, since they tend to cite the same references. It is observed in general, that Spanish universities have a strong presence in the journal. However, unlike other analysis, in which the institutions of the same country are usually coupled bibliographically (see for example, [36] [37] [12] [13], this visualization does not allow to observe a marked clustering by institutions of the same country. One explanation for this is that IJIMAI is still in an expansion stage and it is likely that institutions and researchers from the same country still do not know the journal.
Another interesting analysis to carry out is the bibliographic coupling at the country level. Remember that the visualization of this technique shows the countries that publish the most in the journal and that tend to cite the same documents. Fig. 7 shows the bibliographic coupling of the countries that publish in IJIMAI with a minimum threshold of one study and one hundred more representative links.

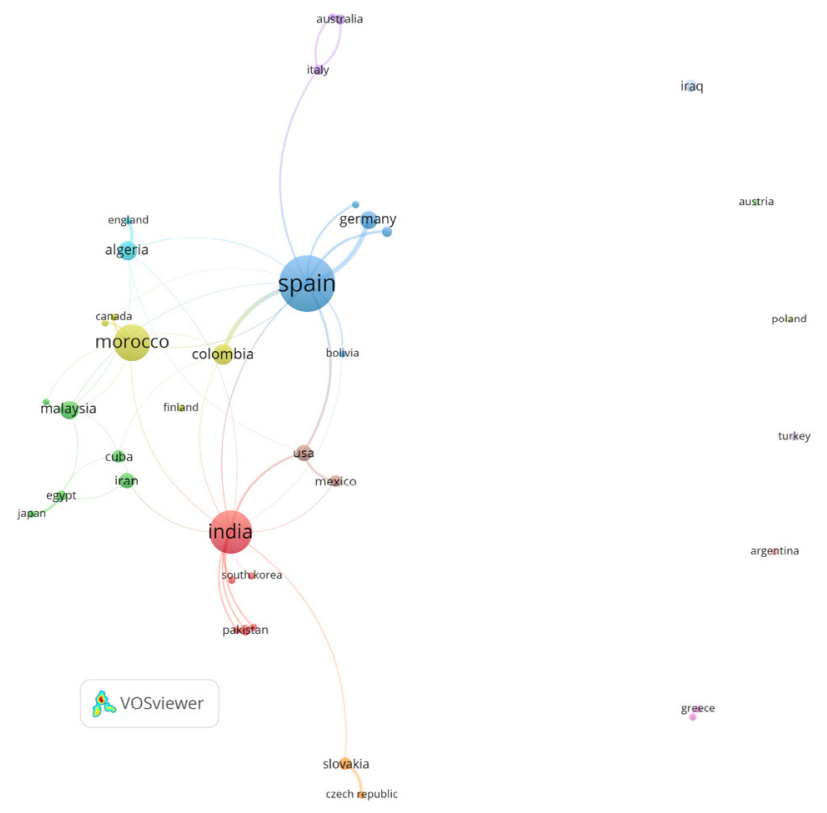

Fig. 7. Bibliographic coupling of countries publishing in IJIMAI: minimum publication threshold of 1 and 100 links.

Note that the most productive countries in the journal are Spain, India and Morocco. The case of this last country, is especially striking. Morocco has been implementing several policies aimed at the development of ICTs in the country, that is probably motivating research in scientific fields related to IJIMAI. On the other hand, and as in the previous visualization, there is no clear bibliographic coupling between neighboring countries. We believe, however, that as IJIMAI grows and positions itself among related journals, the nearby countries will tend to be bibliographically coupled with more notoriety.

Finally, we perform an analysis of co-occurrences of keywords [31]. The keywords can be extracted from the title and the summary of a publication, or also they can be obtained from the list of keywords provided by the author of a publication. According to van Eck and Waltman [38], the number of co-occurrences of two keywords is the number of publications in which both keywords appear together in the title, summary or list of keywords. In such a way, Fig. 8 presents the cooccurrence of keywords in the IJIMAI publications, with a minimum threshold of two co-occurrences and one hundred more representative links.

The visualization of Fig. 8 shows that a good diversity of terms is used in the publications of the journal. Although the terms most frequently used in publications are Big Data, Machine Learning, Artificial Intelligence and Classification. In general, a first interpretation of the figure is that there is a clear orientation of IJIMAI towards areas more related to Artificial Intelligence and Data Mining. In fact, the clusters located on the left side of the figure are related to the aforementioned areas. In addition, given the closeness of the terms, it can be assumed that these terms co-occur quite frequently in the IJIMAI publications. Other less frequent clusters are related to disciplines such as Semantic Web and Interactive Multimedia. 


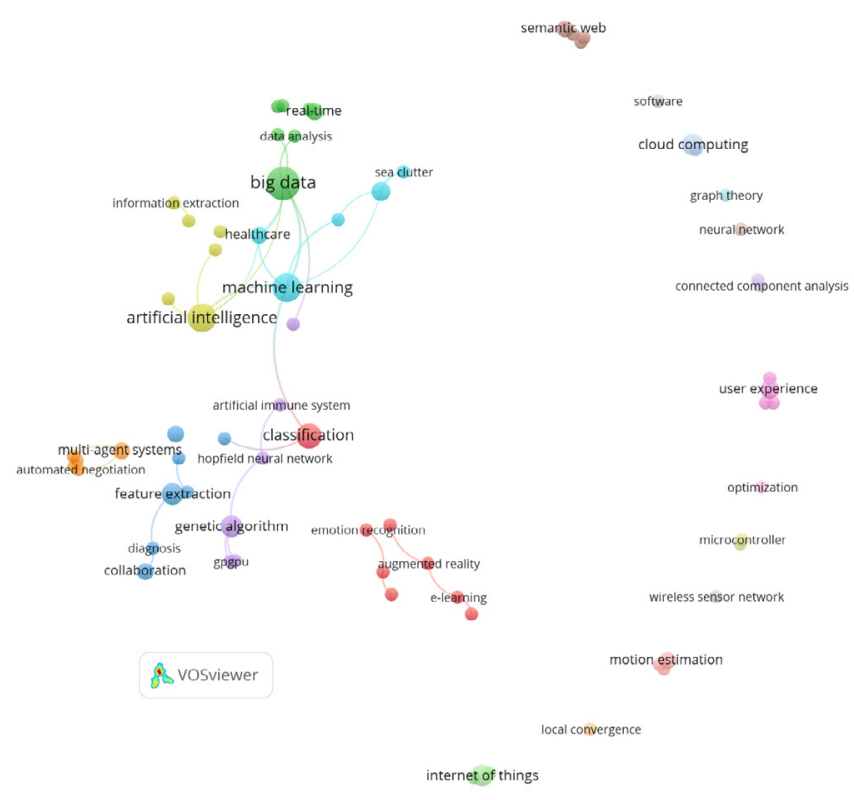

Fig. 8. Co-occurrence of keywords (Keyword Plus) in IJIMAI: minimum occurrence threshold of 2 and 100 links.

\section{CONCLUSIONS}

IJIMAI is a young international magazine related to the Artificial Intelligence and tools that use Artificial Intelligence with interactive multimedia techniques. It celebrates its tenth anniversary in 2018. This fact has motivated the development of this work, which presents a bibliometric description, showing the main tendencies of the journal during its first ten years. This study uses the WoS database mainly, and specifically, the ESCI database, one of the databases of references that are part of the WoS database.

The bibliometric analysis developed was based mainly on science mapping or bibliometric mapping, considered one of the main bibliometric techniques [21]. In order to map the publications of IJIMAI, the VOSviewer software is used, that allows to show the structures of the publications of different scientific actors that have published during the 10 years of the journal. The techniques used in this science mapping are the bibliographic coupling and co-citation of authors, institutions and countries. Additionally, a co-occurrence analysis of keywords is incorporated and the evolution of the publications and the most cited articles of IJIMAI are also shown.

The results show that the co-cited journals are related to Computer Science and Information Systems in general. Spain, on the other hand, is the country with the largest presence in IJIMAI, a situation that is also common, since IJIMAI is an international journal from the University of La Rioja, located in Spain. This is also explained by a strong presence of Spanish universities publishing in the journal. Other countries that stand out in the journal, are India and Morocco, and to a lesser extent, emerging countries such as Colombia, Bolivia, Iran among several others. The science mapping analysis ends with an analysis of the most frequent and co-occurring keywords among them. In this sense, it can be pointed out that the main areas in which the IJIMAI publications are focused are Big Data, Machine Learning, Artificial Intelligence and Classification.

This work has been done to contribute with a general vision of the state and structure of the investigations published in IJIMAI. Like any document, this work presents some limitations that should be considered. In the first place, it must be taken into account that in the future, the presented data will change because the bibliometric data are dynamic and evolve. Obviously, IJIMAI must continue to grow and position itself among similar journals and the various disciplines that it declares in its scientific scope. This will allow in the future, to develop a more complete bibliometric analysis that involves other complementary methodologies to the scientific mapping, as for example, the analysis of bibliometric performance [20]. By doing this, the document can provide more information that the reader can assess according to their interests and priorities. Secondly, this analysis performs a science mapping analysis taking into account the authors who publish in IJIMAI. However, keep in mind that many of the authors who published in the first issues of the journal, they could change their membership through these ten years, therefore, some of the results shown in this scientific mapping may not represent the current affiliation of some authors. Finally, through this scientific mapping of the publications of IJIMAI, we want to give them our congratulations and encourage them to continue contributing and supporting the development of the various disciplines of interest to the journal.

\section{ACKNOWLEDGEMENTS}

This project was funded by the FEDER financial support from the Project TIN2016-75850-P provided by the Spanish Ministry of Science, Innovation and Universities. The last author acknowledges support from the Fondecyt Regular program (project number 1160286) of the Chilean Government through Conicyt.

\section{REFERENCES}

[1] Cobo, M.J., López-Herrera, A.G., Herrera-Viedma, E., Herrera, F., 2011. An approach for detecting, quantifying, and visualizing the evolution of a research field: A practical application to the Fuzzy Sets Theory field. Journal of Informetrics 5, 146-166.

[2] Van Raan, A., 2005. Handbook of Quantitative Science and Technology Research. Chapter Measuring Science. Springer Netherlands.

[3] Kessler, M.M., 1963. Bibliographic coupling between scientific papers. American Documentation 14, 10-25.

[4] Small, H., 1973. Co-citation in the scientific literature: A new measure of the relationship between two documents. Journal of the American Society for Information Science 24, 265-269.

[5] Van Eck, N.J., Waltman, L., 2010. Software survey: VOSviewer, a computer program for bibliometric mapping. Scientometrics 84, 523-538.

[6] Ding, Y., Rousseau, R., Wolfram, D., 2014. Measuring scholarly impact : methods and practice, Firs Editi. ed. Springer, Cham, Heidelberg, New York, Dordrecht, London.

[7] Podsakoff, P.M., MacKenzie, S.B., Podsakoff, N.P., Bachrach, D.G., 2008. Scholarly influence in the field of management: A bibliometric analysis of the determinants of university and author impact in the management literature in the past quarter century. Journal of Management 34, 641-720.

[8] Bonilla, C., Merigó, J.M., Torres-Abad, C. 2015. Economics in Latin America: A bibliometric analysis. Scientometrics 105, 1239-1252.

[9] Baier-Fuentes, H., Merigó, J.M., Amorós, J.E., Gaviria-Marin, M., 2018. International entrepreneursip, an overview from bibliometric analysis. International Entrepreneurship and Management Journal, https://doi. org/10.1007/s11365-017-0487-y.

[10] Gaviria-Marin, M., Merigó, J.M., Baier-Fuentes, H., 2018. Knowledge management: a global examination based on bibliometric analysis, Technological Forecasting and Social Change, https://doi.org/10.1016/j. techfore.2018.07.006.

[11] Schwert, G.W., 1993. The Journal of Financial Economics A retrospective evaluation (1974-91)*. Journal of Financial Economics 33, 369-424.

[12] Merigó, J.M., Pedrycz, W., Weber, R., de la Sotta, C., 2018. Fifty years of Information Sciences: A bibliometric overview. Information Sciences 432, 245-268.

[13] Merigó, J.M., Blanco-Mesa, F., Gil-Lafuente, A.M., Yager, R.R., 2017. Thirty Years of the International Journal of Intelligent Systems: A Bibliometric Review. International Journal of Intelligent Systems 32, 526-554. 
[14] Cobo, M.J., Martínez, M.A., Gutiérrez-Salcedo, M., Fujita, H., HerreraViedma, E., 2015. 25 years at Knowledge-Based Systems: A bibliometric analysis. Knowledge-Based Systems 80, 3-13.

[15] Biemans, W., Griffin, A., Moenaert, R., 2007. Twenty Years of the Journal of Product Innovation Management: History, Participants, and Knowledge Stock and Flows. The Journal of Product Innovation Management 24, 193-213.

[16] Gaviria-Marín, M., Merigó, J.M., Popa, S. 2018. Twenty years of the Journal of Knowledge Management: A bibliometric analysis, Journal of Knowledge Management 22, 1655-1687.

[17] Cancino, C., Merigó, J.M., Coronado, F., Dessouky, Y., Dessouky, M. 2017. Forty years of Computers \& Industrial Engineering: A bibliometric analysis. Computers \& Industrial Engineering 113, 614-629.

[18] Merigó, J.M., Cobo, M.J., Laengle, S., Rivas, D., Herrera-Viedma, E., 2018. Twenty years of Soft Computing: a bibliometric overview. Soft Computing In Press. doi:10.1007/s00500-018-3168-z.

[19] Pritchard, A., 1969. Statistical Bibliography or Bibliometrics? Journal of Documentation 25, 348-349.

[20] Small, H., 1999. Visualizing science by citation mapping. Journal of the American Society for Information Science 50, 799-813.

[21] Morris, S.A., Van der Veer Martens, B., 2009. Mapping research specialties. Annual Review of Information Science and Technology 42, 213-295.

[22] Cobo, M.J., López-Herrera, A.G., Herrera-Viedma, E., Herrera, F., 2011. Science mapping software tools: Review, analysis, and cooperative study among tools. Journal of the American Society for Information Science and Technology 62, 1382-1402.

[23] Chen, C., 2006. CiteSpace II: Detecting and visualizing emerging trends and transient patterns in scientific literature. Journal of the American Society for Information Science and Technology 57, 359-377.

[24] Persson, O., Danell, R., Wiborg Schneider, J., 2009. How to use Bibexcel for various types of bibliometric analysis, in: Åström, F., Danell, R., Larsen, B., Schneider, J. (Eds.), Celebrating Scholarly Communication Studies: A Festschrift for Olle Persson at His 60th Birthday. International Society for Scientometrics and Infometrics, Leuven, pp. 9-24.

[25] Porter, A.L., Cunningham, S.W., 2005. Tech mining: exploiting new technologies for competitive advantage. John Wiley \& Sons Inc., Hoboken, NJ.

[26] Tur-Porcar, A., Mas-Tur, A., Merigó, J.M., Roig-Tierno, N., Watt, J. 2018. A bibliometric history of the Journal of Psychology between 1936 and 2015. Journal of Psychology 152, 199-225.

[27] Valenzuela, L., Merigó, J.M., Johnston, W., Nicolás, C., Jaramillo, F. 2017. Thirty years of the Journal of Business \& Industrial Marketing: A bibliometric analysis, Journal of Business \& Industrial Marketing 32, 1-18.

[28] Blanco-Mesa, F., Merigó, J.M., Gil-Lafuente, A.M. 2017. Fuzzy decision making: A bibliometric-based review. Journal of Intelligent \& Fuzzy Systems 32, 2033-2050.

[29] Martínez-López, F.J., Merigó, J.M., Valenzuela, L., Nicolás, C. 2018. Fifty years of the European Journal of Marketing: A bibliometric analysis. European Journal of Marketing 52(1-2), 439-468.

[30] Peters, H.P.F., van Raan, A.F.., 1991. Structuring scientific activities by coauthor analysis: An exercise on a university faculty level. Scientometrics 20, 235-255.

[31] Callon, M., Courtial, J.P., Turner, W.A., Bauin, S., 1983. From translations to problematic networks: An introduction to co-word analysis. Social Science Information 22, 191-235.

[32] Mulet-Forteza, C., Martorell-Cunill, O., Merigó, J.M., Genovart-Balaguer, J., Mauleon-Mendez, E. 2018. Journal of Travel \& Tourism Marketing: A bibliometric analysis, Journal of Travel \& Tourism Marketing 35, 1201-1221.

[33] Wang, W., Laengle, S., Merigó, J.M., Yu, D., Herrera-Viedma, E., Cobo, M.J., Bouchon-Meunier, B. 2018. A bibliometric analysis of the first twenty-five years of the International Journal of Uncertainty, Fuzziness and Knowledge-Based Systems. International Journal of Uncertainty, Fuzziness and Knowledge-Based Systems 26, 169-193.

[34] Huang, Y., Zhu, D., Lv, Q., Porter, A.L., Robinson, D.K.R., Wang, X., 2017. Early insights on the Emerging Sources Citation Index (ESCI): an overlay map-based bibliometric study. Scientometrics 111, 2041-2057.

[35] Gutiérrez-Salcedo, M., Angeles Martínez, M., Moral-Munoz, J., HerreraViedma, E., Cobo, M., 2018. Some bibliometric procedures for analyzing and evaluating research fields. Applied Intelligence 48, 1275-1287.
[36] Cancino, C.A., Merigó, J.M., Coronado, F.C., 2017. A bibliometric analysis of leading universities in innovation research. Journal of Innovation \& Knowledge 2, 106-124.

[37] Laengle, S., Merigó, J.M., Miranda, J., Słowínski, R., Bomze, I., Borgonovo, E., Dyson, R.G., Oliveira, J.F., Teunter, R., 2017. Forty years of the European Journal of Operational Research: A bibliometric overview. European Journal of Operational Research 262, 803-816.

[38] Van Eck, N.J., Waltman, L., 2014. Visualizing Bibliometric Networks, in: Ding, Y., Rousseau, R., Wolfram, D. (Eds.), Measuring Scholarly Impact: Methods and Practice. Springer, pp. 285-320.

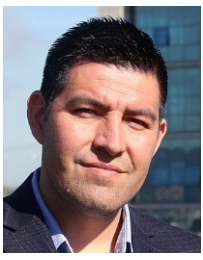

\section{Hugo Baier-Fuentes}

Hugo Baier-Fuentes is a $\mathrm{PhD}$ in Business by the University of Barcelona (Spain). Currently he is an Assistant Professor and Academic Director MBA at the Faculty of Economics and Business Administration at the Universidad Católica de la Santísima Concepción, Chile. He also holds a Bachelor in Industrial Engineering from the Adventist University of Chile. He has published in several international journals including Technological Forecasting and Social Change, European Journal of International Management and International Entrepreneurship and Management Journal. His research includes the study of bibliometrics, international entrepreneurship and the international strategy of Latin American small firms. His works have been presented in the leading conferences of Spain, including Spanish Academy of Management (ACEDE), and the Academy of International Business Conference.

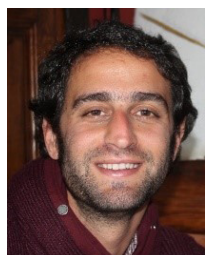

Jesús-Daniel Cascón-Katchadourian

Jesús-Daniel Cascón-Katchadourian is $\mathrm{PhD}$ in Documentation Studies and Master in Documentation and Scientific Communication. He has a degree in History and another in Documentation from the University of Granada. $\mathrm{He}$ received the first national award by the Ministry of Education, Culture and Sport. His interest areas are related with cartography, georeferencing and geolocation of historical photography, bibliometric studies and information retrieval. $\mathrm{He}$ currently enjoys a postdoctoral contract at the University of Granada.

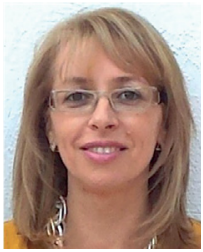

María-Ángeles Martínez-Sánchez

María-Ángeles Martínez-Sánchez is a $\mathrm{PhD}$ in Social Sciences, Master in Information and Scientific Communication, and graduate in Social Work from the University of Granada. She is an Associate professor in the Department of Social Work and Social Services. Her most recent research revolves around science analysis, bibliometric studies, digital libraries, and social services. She is author of 10 JCR publications and different international conference contributions.

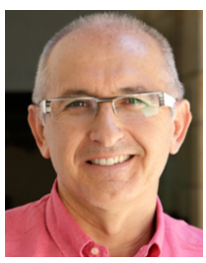

\section{Enrique Herrera-Viedma}

Enrique Herrera-Viedma is Professor in Computer Science and A.I in University of Granada and currently the new Vice-President for Research and Knowledge Transfer and Vice-President for Publications in IEEE SMC Society. His current research interests include group decision making, consensus models, linguistic preference modeling, aggregation of information, information retrieval, bibliometrics, digital libraries, web quality evaluation, recommender systems, social networks, and social media. In these topics he has published more than 250 papers in JCR journals and coordinated more than 20 research projects. Dr. Herrera-Viedma is member of the government board of the IEEE SMC Society and an Associate Editor of several international journals such as the IEEE Trans. On Syst. Man, and Cyb.: Systems, IEEE Trans. On Fuzzy Systems, Knowledge Based Systems, Soft Computing, Fuzzy Optimization and Decision Making, Applied Soft Computing, Journal of Intelligent and Fuzzy Systems, and Information Sciences. Since 2014 he has been selected as a Highly Cited Author in both categories Computer Science and Engineering by Clarivate Analytics. 


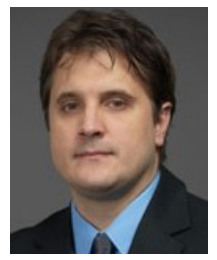

José M. Merigó

José M. Merigó is currently a Full Professor at the School of Information, Systems and Modelling at the Faculty of Engineering and Information Technology at the University of Technology Sydney and a Part-Time Full Professor at the Department of Management Control and Information Systems at the School of Economics and Business at the University of Chile. His research is focused on computational intelligence, decision theory, aggregation operators, bibliometrics and uncertainty. He has been a Senior Research Fellow at the Manchester Business School of the University of Manchester (UK) and Senior Assistant Professor at the University of Barcelona at the Department of Business Administration. He has published $>500$ papers including 20 books and $>200$ publications indexed in Web of Science Core Collection. He is an editorial board member of several international journals including Computers \& Industrial Engineering, Applied Soft Computing, Kybernetes, Technological and Economic Development of Economy, International Journal of Fuzzy Systems and Journal of Intelligent \& Fuzzy Systems. Since 2015 he has been selected as a Highly Cited Author in Computer Science by Clarivate Analytics. 